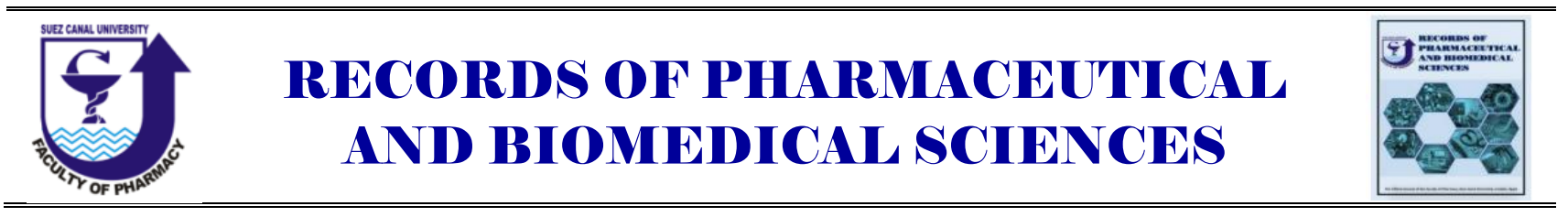

\title{
Phytochemical investigation and cytotoxic activity of Hedera helix ssp rhizomatifera leaves
}

\author{
Samah M. El Sohafy ${ }^{a}$, Safa M. Shams Eldin ${ }^{a}$, Rasha A. Nassra ${ }^{b}$,Shaimaa M. Sallam ${ }^{a}$ \\ ${ }^{a}$ Department of Pharmacognosy, Faculty of Pharmacy, Alexandria university, Egypt, ${ }^{b}$ Department of Medical \\ Biochemistry, Faculty of Medicine, Alexandria university, Egypt.
}

Received on: 15. 06. 2020

Revised on: 27. 06. 2020

Accepted on: 29. 06. 2020

Correspondence Author:

Tel: +01111663399

E-mail address:

samahelsohafy@yahoo.com

\begin{abstract}
Hedera helix rhizomatifera L. plant belongs to the family Araliaceae. It is a host of a wide variety of bioactive compounds (mainly triterpenoidal saponins and phenolic compounds) of several biological activities; including spasmolytic, antiinflammatory, antimicrobial and many other activities. It is widely marketed as a herbal cough remedy. The aim of the present study was the phytochemical investigation of the species rhizomatifera, in addition to the assessment of its cytotoxicity on target cancer cell lines. Our results indicated that H. helix spp. rhizomatifera manifested a significant cytotoxic activity against Human hepatocellular carcinoma cell line (HepG2) and human breast cancer cell line (MCF7) with $\mathrm{IC}_{50}$ reaching 1.9125 and $2.0823 \mu \mathrm{g} / \mathrm{ml}$ respectively, in comparison to 1.549 and $1.02 \mu \mathrm{g} / \mathrm{ml}$ respectively for Doxorubicin. The UPLC-ESI-MS/MS study revealed the presence of 24 compounds, 15 of which were tentatively identified as triterpenoidal saponins, flavonoids mainly kaempferol and quercetin derivatives, in addition to some phenolic acids.
\end{abstract}

Keywords: Hedera helix- Rhizomatifera - Araliaceae - UPLC-ESI-MS/MScough remedy.

\section{Introduction:}

Hedera helix $\mathrm{L}$. is a well-known plant widely known as "Habl Almasakeen" and "Leblab Kabeer" in Arabic and the "Ivy" in English, (Araliaceae). It consists of approximately 15 species distributed throughout Europe and North Africa (Ackerfield, 2001; Ackerfield and Wen, 2002). Members of such genus are highly valued as ornamentals. The common ivy is a climbing evergreen woody plant mostly found on different trees, walls as well as trailing type on the ground (Al-Snafi, 2018). It has a big reputation as a homeopathic medicine, in the treatment of respiratory infections and common cold associated with cough, as an analgesic and antiinflammatory preparations (Gul et al., 2018). The boiled leaves of H. helix was used as an anthelmintic for ringworm and in diabetes (Al-Snafi, 2018). Commercial dry extract of ivy leaves exhibit antispasmodic, anti-inflammatory and antimicrobial activities for acute catarrh and 
symptomatic treatment of chronic inflammatory bronchial diseases (Khdair et al. 2010; Hussien and Awad, 2014; Al-Snafi, 2018). It also showed hepatoprotective, antioxidant, hypoglycaemic, antimutagenic and antihyaluronidase activities (Hussien and Awad, 2014), that is why H. helix leaf extract is approved by the German Commission E (Trute and Nahrstedt, 1997; Khdair et al. 2010). Topically, the extract of $H$. helix is used in the treatment of cellulite (liprosclerosis) and for weight loss (Gul et al., 2018). H. helix extract is also used as an emollient and for itch relieving (Lutsenko et al., 2010; Gul et al., 2018).

These activities were attributed to the biologically active compounds mainly the triterpenoid saponins. These saponins are grouped into several classes including the bidesmosidic glycosides of hederagenin and oleanolic acid (namely hederacoside $\mathrm{B}, \mathrm{C}, \mathrm{D}, \mathrm{E}, \mathrm{F}, \mathrm{G}, \mathrm{H}, \mathrm{I})$ and the monodesmoside ( $\alpha$-hederin). These compounds are responsible for its $\beta 2$ - adrenergic effects, which leads to the bronchodilatory, spasmolytic, mucolytic and expectorant action (Gul et al., 2018). Furthermore, the presence of phenolics (flavonoids; mainly rutin), anthocyanins, coumarins which partly contribute to the antispasmodic activity and phenolic acids (rosmarinic acid), amino acids, steroids ( $\beta$ sitosterol), volatile oil (methylethyl ketone) (Lutsenko et al., 2010), fixed oils (Trute and Nahrstedt, 1997; Khdair et al. 2010; Hussien and Awad, 2014) and polyines (e.g. falcarinol).

Although our literature survey revealed large occurrence of reports on $\mathrm{H}$. helix, there were only rare studies concerning the ssp. rhizomatifera cultivated in Holland, accordingly, the objective of this study was to develop a simple and reliable analytical method for the detection of the marker compounds to help in the chemical profiling of this plant by the use of ultra-performance liquid chromatography (UPLC) coupled with Mass detection. This method can be used efficiently for routine quality control and analysis. The challenge in the development of such a method is attributed to the presence of the marker compounds known as hederacoside $\mathrm{C}$ and hederasaponin $\mathrm{B}$ as well as other minor saponins and phenolic constituents all together in a complex matrix. In addition to studying the cytotoxic activity of this species against Human hepatocellular carcinoma cell line (HepG2), and human breast cancer cell line (MCF7).

\section{Experimental}

\subsection{Plant material}

Hedera helix ssp rhizomatifera was imported from Holland. Sample identification and authentication was carried out by the department of ornamental plants, Faculty of Agriculture, Alexandria University. A voucher sample with the number IVY03-2019 was kept at the department of pharmacognosy, Faculty of Pharmacy, Alexandria University.

\subsection{Preparation of extract}

Dried Hedera helix L. leaves were powdered, and 10 $\mathrm{g}$ of the powder was extracted with $70 \%$ ethanol for $48 \mathrm{~h}$. The extract was filtered and evaporated at 45 ${ }^{\circ} \mathrm{C}$ under reduced pressure until all solvent was removed. For the in vitro cytotoxicity assay, $10 \mathrm{mg}$ of the extract was dissolved in $10 \mathrm{ml}$ DMSO.

\subsection{Chemicals}

All solvents used were of analytical grade, ultrapure water, methanol, acetonitrile and formic acid 
were obtained from Fisher Scientific, UK and they were of UPLC grade.

\subsection{Analysis of the Hedera helix ssp rhizomatifera extract by Ultra-High Performance Liquid Chromatography coupled to Mass Spectrometry (UPLC- ESI-MS/MS)}

\subsubsection{Sample preparation for UPLC-ESI- MS/MS analysis}

The sample was prepared at $1 \mathrm{mg} \cdot \mathrm{ml}^{-1}$ concentration using HPLC-grade methanol, filtered using nylon membrane disc filter $(0.2 \mu \mathrm{m})$ and degassed by sonication before being loaded for analysis. Full loop injection volume $(10 \mu \mathrm{L})$ of the sample was applied onto the chromatographic column.

\subsubsection{Instrument and UPLC conditions}

Assignment of the secondary metabolites present in Hedera helix ssp rhizomatifera was performed using an UPLC XEVO TQD coupled with triple quadruple mass spectrometer, Milford, MA01757 U.S.A, Waters Acquity QSM binary pump, a LC-2040 (Waters) autosampler, degasser and Waters Acquity $\mathrm{CM}$ detector.

A Waters Acquity UPLC BEH C18 column $(50 \mathrm{~mm}$ $\times 2.1 \mathrm{~mm} \mathrm{ID} \times 1.7 \mu \mathrm{m}$ particle size) operating at a flow rate of $0.2 \mathrm{ml} . \mathrm{min}^{-1}$ and the column temperature was set at $30^{\circ} \mathrm{C}$.

The analyses were carried out using a binary mobile phase consisted of ultrapure water $+0.1 \%$ formic acid (Phase A) and acetonitrile $+0.1 \%$ formic acid (Phase B). $0.1 \%$ formic acid is the most proper when using MS detector providing a distinct influence on analyte responses and ionization efficiency. Gradient elution is considered compulsory in recognition of the complexity of herbal extracts. The gradient elution programmed as follows: $0.0-2.0 \mathrm{~min}, 5 \% \mathrm{~B} ; 2.0-12.0 \mathrm{~min}, 50 \% \mathrm{~B}$; 12.0-24.0 min, $80 \%$ B; 27.0min, 90\% B; 29.0 min, $90 \% \mathrm{~B} ; 30.0-33.0 \mathrm{~min}, 5 \% \mathrm{~B}$. Then $4 \mathrm{~min}$ at the initial conditions to re-equilibrate the column.

\subsubsection{ESI-MS/MS conditions}

Triple quadruple mass spectrometer, QQQ mass spectrometer (Milford, MA01757 U.S.A) connected to UPLC XEVO TQD system was used in the ESI (Alberti, 2014) in negative ion mode. Also regarding the mass analyzers, Triple quadrupole (TQD) or tandem mass acts as a powerful, highly selective tool for the ions of interest as it is specifically designed for detection over a single-stage MS operation where the target ion (parent ion) from initial fragmentation is directly transmitted to further fragmentation steps $\left(\mathrm{MS}^{\mathrm{n}}\right)$ to allow for more detailed structural information (Bankova et al., 2019).

The optimized ESI operating conditions were as follows: capillary voltage of $3 \mathrm{kV}$, cone voltage; 35 $\mathrm{V}$, the ion source temperature was $150{ }^{\circ} \mathrm{C}$, the nebulizer (nitrogen gas) pressure was $35 \mathrm{psi}$, drying and sheath gas $\left(\mathrm{N}_{2}\right)$ temperature was $440{ }^{\circ} \mathrm{C}$ and 350 ${ }^{\circ} \mathrm{C}$, respectively. The drying and sheath gas flows were applied at $900 \mathrm{~L} / \mathrm{h}$ and $50 \mathrm{~L} / \mathrm{h}$, respectively. The analytical run time was extended to $30 \mathrm{~min}$. MS spectra were achieved by full range acquisition covering $100-1400 \mathrm{~m} / \mathrm{z}$. To optimize the MS/MS conditions of all the compounds, they were set up by confirming the fragment patterns and changing the collision energies for each compound for the scanning types, Product ion and the Multiple Reaction Monitoring (MRM) mode. 
This can be explained as MS spectra were achieved by full range acquisition covering $100-1400 \mathrm{~m} / \mathrm{z}$. The precursor ions which were mass-selected by the first quadrupole (Q1), the collision-induced dissociation (CID) energy was ramped from 30 to $70 \mathrm{eV}$ using nitrogen gas as a collision gas in the second quadrupole collisional cell (Q2). In the negative ion mode, fragmentations were improved with collision energies (Bankova et al., 2019) Finally, the daughter ions yielding from CID are consequently related to the molecular structure of the precursor ions and can be monitored by a third quadrupole mass analyzer (Q3). Metabolite assignments were established according to MS data (quasi-molecular ions as well as diagnostic MS/MS fragmentation profiles) compared to reference literature and phytochemical dictionary of natural products database (CRC) to provide higher confidence level of annotation.

\subsection{Cell Viability assay}

\subsubsection{Cell culture}

Human hepatocellular carcinoma cell line (HepG2) and human breast cancer cell line (MCF7) were preserved and obtained frozen in liquid nitrogen ($180{ }^{\circ} \mathrm{C}$ ) from Vacsera, Giza, Egypt. Cells were cultivated in high glucose Dulbecco's Modified Eagle Medium (DMEM) with $2 \mathrm{mM}$ L-glutamine (Lonza, Switzerland), supplemented with $10 \%$ fetal bovine serum FBS (Seralab, UK), and $100 \mathrm{U} / \mathrm{ml}$ penicillin / $2 \mathrm{mg} / \mathrm{ml}$ streptomycin (Invitrogen Corporation, Grand Island, NY) in T25 culture flasks (CELLSTAR ${ }^{\circledR}$, Greiner Bio-One) at $37^{\circ} \mathrm{C}$ in a $5 \%$ $\mathrm{CO}_{2}, 95 \%$ humidified air incubator. Exponentially growing cells were trypsinized (Trypsin-EDTA, Lonza, Switzerland) and re-suspended in antibiotic-containing medium (100 units penicillin $\mathrm{G}$ and $0.1 \mathrm{mg}$ of streptomycin $/ \mathrm{ml}$ ). Cells showing $70-90 \%$ confluency were harvested and subsequently counted. After counting, dilutions were made to give the appropriate cell densities, $1 \mathrm{x}$ $10^{6}$ cells $/ \mathrm{ml}$ for inoculation onto 96 -well microtiter plates (final cell number/well was equal to $1 \times 10^{5}$ cells in $100 \mu \mathrm{l}$ culture media) and incubated for 24 hours before addition of the test extracts. Doxorubicin (ALEXIS Biochemicals, Lausen Switzerland) was used as a positive control. Cells were exposed to different concentrations of the studied extracts and Doxorubicin. Test extracts were serially diluted by dissolving in DMSO followed by dilution with DMEM to yield the final DMSO concentration in the assay well as $0.2 \%$. Stock solutions of studied extracts were prepared and further diluted to yield concentrations ranging from $1000-31.25 \mu \mathrm{g} / \mathrm{ml}$. Solutions of test samples at the desired dilutions were added in triplicates to the wells containing the cells and incubated for $48 \mathrm{~h}$ before applying the Neutral Red assay.

\subsubsection{In vitro cytotoxicity by neutral red uptake} assay

Anti-proliferative activity against the two cell lines was estimated by the neutral red (3-amino-7dimethylamino-2-methyl-phenazine hydrochloride) (Sigma, cat. no. N4638) (Winckler, 1974; Ates et $a l ., 2017)$ which is based on the ability of viable cells to incorporate and bind the supravital dye neutral red. This weakly cationic dye penetrates cell membranes and concentrates in the lysosomes by nonionic passive diffusion. An acidified ethanol solution was then used for the extraction of the dye 
Table 1. UPLC-ESI-MS/MS of Hedera helix ssp rhizomatifera leaves

\begin{tabular}{|c|c|c|c|c|c|}
\hline $\begin{array}{c}\text { Compound } \\
\text { number }\end{array}$ & Compound name & Rt/min & MW & $\begin{array}{l}\text { Fragments } \\
(\mathbf{m} / \mathbf{z})\end{array}$ & MS/MS fragments \\
\hline 1 & Phloretin (dihydrochalcone) & 0.8 & 274 & $273[\mathrm{M}-\mathrm{H}]^{-}$ & 167 \\
\hline 2 & Syringaldehyde & 0.91 & 182 & $181[\mathrm{M}-\mathrm{H}]^{-}$ & 183,153 \\
\hline 3 & Quinic acid & 1.2 & 192 & $191[\mathrm{M}-\mathrm{H}]^{-}$ & $173,127,111,85$ \\
\hline 4 & Unidentified peak & 6.63 & - & - & - \\
\hline 5 & Kampferol rhamnoside & 7.17 & 432 & $431[\mathrm{M}-\mathrm{H}]^{-}$ & 285,112 \\
\hline 6 & Unidentified peak & 7.46 & - & - & - \\
\hline 7 & Di-Caffeoyl quinic acid & 8.01 & 516 & $515[\mathrm{M}-\mathrm{H}]^{-}$ & $353,179,143,126$ \\
\hline 8 & Unidentified peak & 8.55 & - & - & - \\
\hline 9 & Caffeoyl moiety & 8.87 & 180 & $\begin{array}{c}179[\mathrm{M}-\mathrm{H}]^{-} \\
217[\mathrm{M}-2 \mathrm{H}+\mathrm{K}]^{-}\end{array}$ & - \\
\hline 10 & Unidentified peak & 9.44 & - & - & - \\
\hline 11 & Gallic acid monohydrate & 9.63 & 188 & $187[\mathrm{M}-\mathrm{H}]^{-}$ & 169,125 \\
\hline 12 & Unidentified peak & 9.73 & - & - & - \\
\hline 13 & Unidentified peak & 10.10 & - & - & - \\
\hline 14 & Unidentified peak & 11.1 & - & 517 & - \\
\hline 15 & Hederacoside C & 11.45 & 1221 & $\begin{array}{c}1220[\mathrm{M}-\mathrm{H}]^{-} \\
749 \text { [genin-H] }^{-}\end{array}$ & 749,469 \\
\hline 16 & Hederasaponin B & 12.05 & 1205 & $1204[\mathrm{M}-\mathrm{H}]^{-}$ & 492 \\
\hline 17 & Unidentified peak & 12.72 & - & - & - \\
\hline 18 & Staunoside A & 12.99 & 958 & $957[\mathrm{M}-\mathrm{H}]^{-}$ & $471,405,393$ \\
\hline 19 & $\begin{array}{l}\text { Isoquercetrin (quercetin-3- } \\
\text { glucoside) }\end{array}$ & 13.8 & 464 & $\begin{array}{l}463[\mathrm{M}-\mathrm{H}]^{-} \\
485[\mathrm{M}- \\
2 \mathrm{H}+\mathrm{Na}]^{-}\end{array}$ & 301 \\
\hline 20 & $\alpha$-hederin & 15.01 & 750 & $749[\mathrm{M}-\mathrm{H}]^{-}$ & 471 \\
\hline 21 & $\begin{array}{c}\text { 3-O- } \beta \text {-D-glucopyranosyl- }(1 \rightarrow 2)- \\
\beta \text {-D-glucopyranosyl oleanolic } \\
\text { acid } \\
\end{array}$ & 15.47 & 796 & $795[\mathrm{M}-\mathrm{H}]^{-}$ & 633,457 \\
\hline 22 & $\begin{array}{l}\text { 3-O- } \beta \text {-D-glucopyranosyl-( }(1 \rightarrow 2) \text { - } \\
\beta \text {-D-glucopyranosyl hederagenin }\end{array}$ & 17.59 & 780 & $779[\mathrm{M}-\mathrm{H}]^{-}$ & 649,673 \\
\hline 23 & Unidentified peak & 20 & - & - & - \\
\hline 24 & Kaempferol-3-rutinoside & 23.5 & 595 & $594[\mathrm{M}-\mathrm{H}]^{-}$ & $285,267,257$ \\
\hline
\end{tabular}

Table 2. In Vitro cytotoxic effect of $H$. helix spp. rhizomatifera and doxorubicin (positive control) against Human Cancer Cell Lines Hep-G2 \& MCF7.

\section{$\mathrm{IC}_{50}(\mu \mathrm{g} / \mathrm{ml})$}

\begin{tabular}{lll}
\hline & Hep-G2 & MCF7 \\
\hline H. helix spp. rhizomatifera & $1.9125 \pm 0.06$ & $2.0823 \pm 0.04$ \\
Doxrubicin & $1.549 \pm 0.08$ & $1.020 \pm 0.09$ \\
\hline
\end{tabular}

Data are presented as (Mean \pm S.E.). 


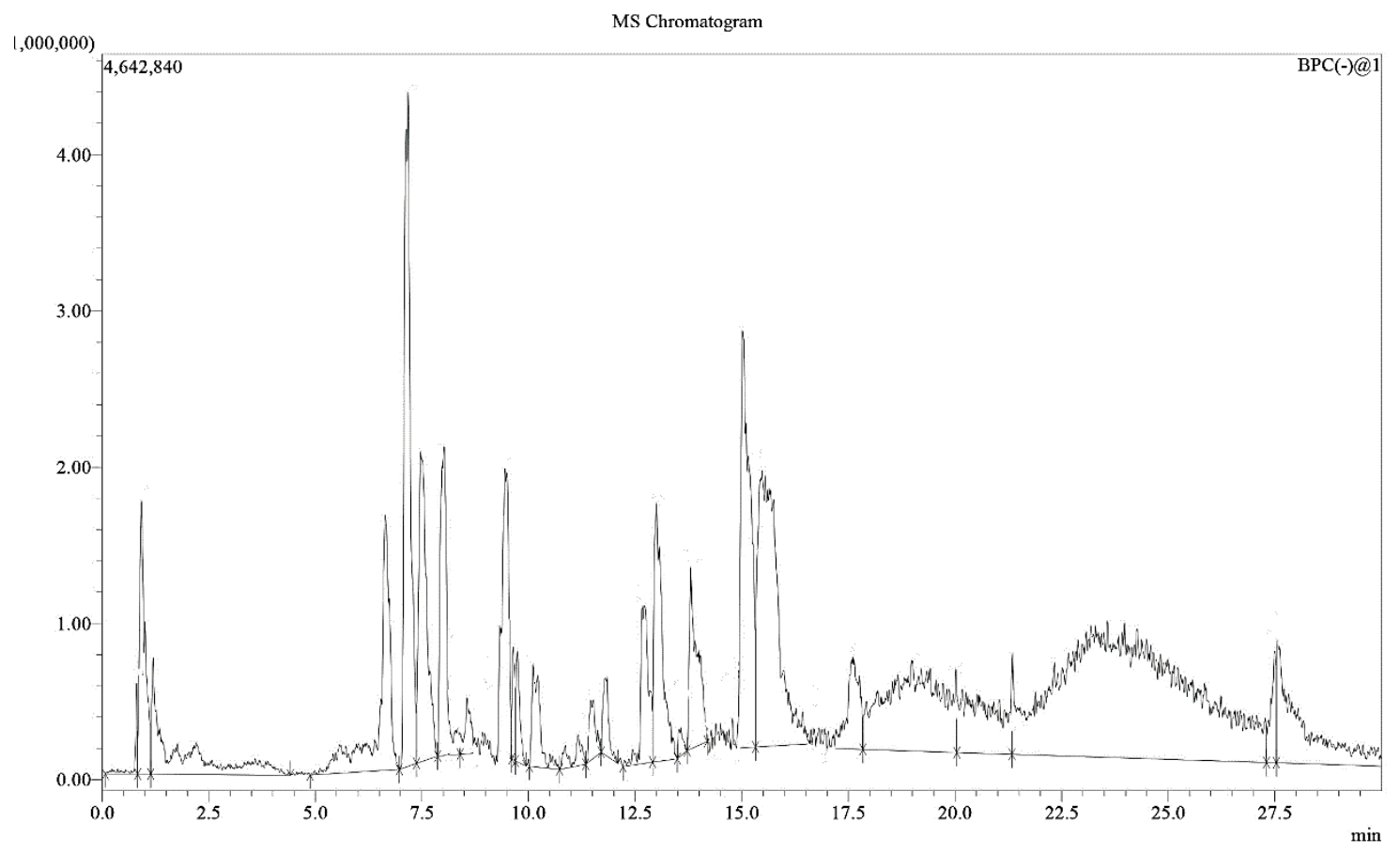

Figure 1: UPLC chromatogram of $\boldsymbol{H}$. helix spp. rhizomatifera.

was from the viable cells, and the absorbance of the solubilized dye was quantified by the use of a spectrophotometer. The color absorbance of each well was recorded in a Bio-Rad microplate reader at $540 \mathrm{~nm}$, where DMSO was used as a blank. The half maximal growth inhibitory concentration $\left(\mathrm{IC}_{50}\right)$ value of the test extracts as well as Doxorubicin was calculated.

The relative cell viability was expressed as the mean percentage of viable cells compared to control nontreated cells and the $\mathrm{IC}_{50}$ of the studied extracts and Doxorubicin were calculated by the trend line equation. All samples and positive control were tested in triplicates and were statistically studied by ANOVA test. Differences between the control and doxorubicin or the tested extract were compared for significance. Values are presented as mean \pm S.E. at $(\mathrm{p}<0.05)$.

Viability $\%=$ Average absorbance (OD) test $/$ Average Absorbance (OD) control x100

\section{Results and Discussion}

\subsection{UPLC-ESI-MS/MS analysis}

\subsubsection{Optimization of UPLC Conditions}

In our study LC-MS analysis coupled with an electrospray ion source was performed for the methanol extract of dried $H$. helix spp. Rhizomatifera leaves in order to identify the different components of the extract (Figures 1 and 2). Thus, a new composition for the mobile phase was optimized. Formic acid in water and acetonitrile were selected as the mobile phase due to their volatility and resolution. As a result, chromatographic separation of 15 compounds from the ivy leaf extract (Six phenolic compounds, three flavonoids and six triterpenoidal saponins) (Table 1) was successfully achieved on the YMC hydrosphere C18 UPLC column within 25 min, with improved separation time (Yu et al., 2015). 


\subsubsection{Optimization of the ESI-MS/MS Conditions}

The experimental parameters used in the MS analysis, including ionization mode, nebulizer gas, pressure, temperature, electrospray voltage, and collision energy were optimized in both polarities (positive and negative) of the electrospray ionization (ESI). The fragmentation of all compounds was conducted in negative mode, due to showing more observable peaks, thus wide range of information compared to positive ion mode (Bankova et al., 2019) (Table 1).

All compounds were detected with the formation of $[\mathrm{M}-\mathrm{H}]^{-}$and $[\mathrm{M}-2 \mathrm{H}+\mathrm{Na}]^{-}$pseudo-molecular ions in negative ESI mode. Among them, three phenolics were displayed with $[\mathrm{M}-\mathrm{H}]^{-}$at $\mathrm{m} / \mathrm{z} 273,181$ and 187 , they were identified as phloretin, syringaldehyde (Fernandes et al., 2017) and gallic acid monohydrate. Six saponins were identified through their $[\mathrm{M}-\mathrm{H}]^{-}$ ions at m/z 1220 (Hederacoside C), 1204 (Hederasaponin B), 957 (Staunoside A; 3-O- $\beta$-Dglucopyranosyl hederagenin 28-O- $\beta$-Dglucopyranosyl-(1 $\rightarrow 6$ )- $\beta$-D-glucopyranosyl ester), 749 ( $\alpha$-hederin), 795 (3-O- $\beta$-D- glucopyranosyl $(1 \rightarrow 2)-\beta$-D-glucopyranosyl oleanolic acid) and 779 (3-O- $\beta$-D-glucopyranosyl- $(1 \rightarrow 2) \quad-\beta \quad$-Dglucopyranosyl hederagenin) (Figure 2) (Kim et al., 2017). In addition, we selected these pseudomolecular ions as the precursor ions, which were consequently broken into fragment ions by tested collision energies determined in the MS/MS mode. The general MS/MS fragmentation pattern of dicaffeoylquinic acid (diCQAs) was summed up as following: the ion peaks at m/z $515[\mathrm{M}-\mathrm{H}]^{-}$which was definitively identified as 1,3 or 3,5 dicaffeoylquinic acid, m/z 191 [quinic acid - H $\left.2 \mathrm{C}_{9} \mathrm{H}_{6} \mathrm{O}_{3}\right]^{-}$(the characteristic fragment ions for quinic acid nucleus existed as base peak) and finally the strong caffeoyl characterization fragments at $\mathrm{m} / \mathrm{z}$ 179 (Ruan et al. 2019). This feature might be caused by the axial conformation of 5-caffeoyl group, causing easy cleavage of 5-caffeoyl group from the quinic acid nucleus to form relatively stable fragmentation ions of both quinic acid and caffeoyl group. Therefore, it was suggested that when C-3 or C-5 was substituted by caffeoyl, a peak at m/z 179 must be an indicator ion. This was explained by the ester bond cleavage between caffeoyl and quinic acid groups, quinic acid dehydration, along with caffeoyl decarbonylation (Ruan et al. 2019).

Fragments at m/z 431 was observed in Kaempferol rhamnoside referring to $[\mathrm{M}-\mathrm{H}]^{-}$. Kaempferol-3rutinoside showed a characteristic peak at m/z 594 as the most intense peak referring to $[\mathrm{M}-\mathrm{H}]^{-}$. Isoquercetrin (quercetin-3-glucoside) was displayed with a fragment at $\mathrm{m} / \mathrm{z} 463$ and 485 as the most intense peak, which may be possibly owing to [M$\mathrm{H}]^{-}$and $[\mathrm{M}-2 \mathrm{H}+\mathrm{Na}]^{-}$, respectively.

Specific fragments of the precursor ions were applied to simultaneously determine each compound in the ivy leaf extract (Table 1) (Madl et al., 2006; HL et al., 2015; Karar and Kuhnert, 2015; Rehmana et al., 2016; Zhou et al., 2018).

\subsection{Cytotoxic activity}

Literature survey shows some studies that confirms the cytotoxicity studies of $H$. helix generally against different cell lines but to our knowledge, not much information is available about the 

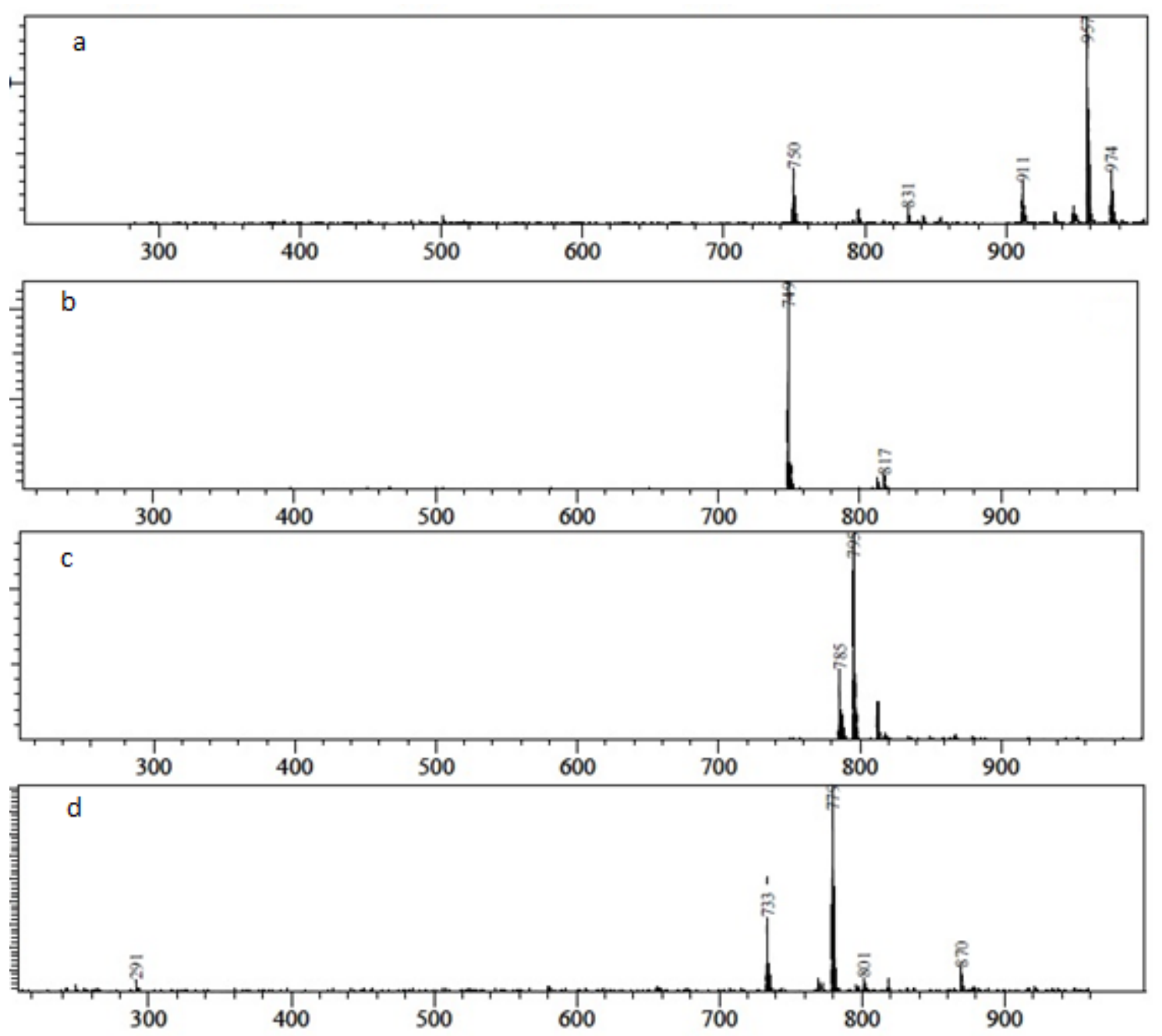

Figure 2: $[\mathrm{M}-\mathrm{H}]^{-}$ions of selected saponins (a) staunoside A, (b) $\alpha$-hederin, (c) 3-O- $\beta$-Dglucopyranosyl-(1 $\rightarrow 2)$ - $\beta$-D-glucopyranosyl oleanolic acid and $(d)$ 3- $O$ - $\beta$-D-glucopyranosyl-(1 $\rightarrow 2$ )- $\beta$-D-glucopyranosyl hederagenin.

influence of H. helix spp. Rhizomatifera on different cancer cell lines.

In the present study, $H$. helix spp. Rhizomatifera extract showed strong cytotoxic activity when compared to Doxorubicin against Hep-G2 and MCF7 cell lines with an $\mathrm{IC}_{50}$ reaching 1.9125 and $2.0823 \mu \mathrm{g} / \mathrm{ml}$ respectively, in comparison to 1.549 and $1.02 \mu \mathrm{g} / \mathrm{ml}$ respectively for Doxorubicin. (Table $1)$.

An apoptosis inducing effect of hederagenin from the leaves of ivy in human colon cancer LoVo cells was previously demonstrated by (Liu et al., 2014) through disruption of mitochondrial membrane potential.

Another study (Kim et al., 2017) conducted on cisplatin-resistant cancer cells revealed that hederagenin enhances ROS levels by inhibiting the Nrf2-ARE pathway, which exerts an essential role in redox homeostasis.

\section{Conclusion}

Natural products were always the main source of drugs used by human population since the start of life on Earth and is still providing us with great 
candidates that chemical synthesis never provide. Medicinal plants can provide a safer alternative for cancer therapy according to availability in each country. From the studies performed, our observations revealed that the studied extract can be a promising candidate for use as an anticancer agent. However, further in vitro studies for the isolates and more importantly in vivo studies need to be carried out for delineating and unraveling the exact mechanism(s) of action of this extract and its constituents in inhibition of proliferative activity of cancer cells.

In our study, a newly developed, rapid and sensitive UPLC-ESI-MS/MS method was established to simultaneously determine 15 compounds, including saponins and phenolics in the ivy leaf extract. UPLC-ESI-MS/MS can be successfully applied to medicinal drugs containing ivy leaf extracts and its quality control.

\section{References:}

Ackerfield, J. and Wen, J., 2002. Morphometric analysis of Hedera L. (the ivy genus, Araliaceae) and its taxonomic implications. ADANSONIA, sér, 24 (2), 197-212.

Ackerfield J., 2001. Trichome morphology in herba (Araliacea). Edinb. J. Bot., 58 (2), 259-267.

Alberti, Á., 2014. LC-ESI-MS/MS methods in profiling of flavonoid glycosides and phenolic acids in traditional medicinal plants: Sempervivum tectorum L. and Corylus avellana $\mathrm{L}$.

Al-Snafi, E. A., 2018. Pharmacological and therapeutic activities of Hedera helix- A review. IOSR Journal of Pharmacy, 8 (5), 41-53.

Ates, G., Vanhaecke, T., Rogiers, V., Rodrigues, R. M., 2017. Assaying Cellular Viability Using the Neutral Red Uptake Assay. Methods Mol. Biol., 16 (1), 19-26.
Bankova, V., Bertelli, D., Borba, R., Conti, B. J., da Silva Cunha, I. B., Danert, C., Moreno, M. I. N., 2019. Standard methods for Apis mellifera propolis research. Journal of Apicultural Research, 58(2), 149.

Fernandes, L., Pereira, J., Lopéz-Cortés, I., Salazar2, D., M., González-Álvarez, J., 2017. Physicochemical composition and antioxidant activity of several pomegranate (Punica granatum L.) cultivars grown in Spain. Eur Food Res Technol 243:1799-1814 DOI 10.1007/s00217-017-2884-4.

Gul, R., Jan, S., Ahmad M., Mukhtiar, M., 2018. Formulation of Hedera helix L. in Topical Dosage Forms: In Vitro and Ex Vivo Evaluation. Dissolution Technologies, 25 (2). DOI: 10.14227/DT250218P40

HL, L., ZM, Q., HD, C., Tan, Y., 2015. Determination of $\alpha$-hederin in rat plasma using liquid chromatography electrospray ionization tandem mass spectrometry (LC-ESI-MS/MS) and its application to a pharmacokinetic study, Analytical methods, 7(5).

Hussien, A. and Awad, J., 2014. Isolation and Characterization of Triterpenoid Saponin Hederacoside C. Present in the Leaves of Hedera helix L. Cultivated in Iraq. Iraqi J. Pharm. Sci., 23 (2), 33-41.

Karar, M. G. E. and Kuhnert, N., 2015. UPLC-ESIQ-TOF-MS/MS Characterization of Phenolics from Crataegus monogyna and Crataegus laevigata (Hawthorn) Leaves, Fruits and their Herbal Derived Drops (Crataegutt Tropfen), J Chem Biol Ther, 1:1 (DOI: 10.4172/2572-0406.1000102).

Khdair, A., Mohammad, M., Tawaha, K., AlHamarsheh, H., AlKhatib, H., Al-khalidi, B., Bustanji, Y., Najjar, S., Hudaib, M., 2010. A Validated RP HPLC-PAD Method for the Determination of Hederacoside C in Ivy-Thyme Cough Syrup. Int J Anal Chem. DOI: $10.1155 / 2010 / 478143$

Kim, N., Shin, Y., Park, s., Yoo, G., kim, Y., Yoo, H., Kim, S., 2017. Simultaneous Determination of Six Compounds in Hedera helix L. Using UPLCESI-MS/MS. Chromatographia, 80, 1025-1033. 
Kim, E., Baek, S., Shin, D., Lee, J., Roh, J., 2017. Hederagenin Induces Apoptosis in CisplatinResistant Head and Neck Cancer Cells by Inhibiting the Nrf2-ARE Antioxidant Pathway. Oxidative Medicine and Cellular Longevity. Oxid Med Cell Longev.,ID 5498908, 12 pages, DOI:10.1155/2017/ 5498908.

Liu, B., Zhou, J., Li, Y., Zou, X., Wu, J., Gu, J., Yuan, J., Zhao, B., Feng, L., Jai, X., Wang, R., 2014. Hederagenin from the leaves of ivy (Hedera helix $\mathrm{L}$.) induces apoptosis in human LoVo colon cells through the mitochondrial pathway. BMC Complement Altern Med., 14, 412. https://doi.org/10.1186/1472-6882-14-412.

Lutsenko, Y., Bylka, W., Matlawska, I., Darmohray, R., 2010. Hedra helix as a medicinal plant. herba polonica, 56 (1), 83-96.

Madl T., Sterk, H., Mittelbach, M., Rechberger, G.N., 2006. Tandem Mass Spectrometric Analysis of a Complex Triterpene Saponin Mixture of Chenopodium quinoa. journal of American society of mass spectrometry, 17 (6), 795-806.

Rehmana, S. U., Choi, M. S., Kim, I.S., Kim, S.H., Yoo, H. H., 2016. An ultra-high-performance Liquid chromatography-tandem Mass spectrometric Method for the determination of hederacoside C, Drug candidate for respiratory disorder, in rat plasma. Journal of Pharmaceutical and Biomedical Analysis, 129, 90-95.

Ruan, J., Yan, J., Zheng, D., Sun, F., Wang, J., Han,
L., Zhang, Y., Wang, T., 2019. Comprehensive Chemical Profiling in the Ethanol Extract of Pluchea indica Aerial Parts by Liquid Chromatography/Mass Spectrometry Analysis of Its Silica Gel Column Chromatography fractions. Molecules, 24, 2784.

Trute, A. and Nahrstedt, A., 1997. Identification and Quantitative Analysis of Phenolic Compounds from the Dry Extract of Hedera helix. Planta Medica, 63 (9), 177-179.

Yu, M., Shin, Y. J., Kim, N., Yoo, G., Park, S. J., Kim, S. H. ،(2015). Determination of Saponins and Flavonoids in Ivy leaf extracts using HPLCDAD. Journal of Chromatographic Science, 53(4), 478-483.

Yu, M., Shin, Y. J., Kim, N., Yoo, G., Park, S. J., Kim, S. H. '2015. Determination of Saponins and Flavonoids in Ivy leaf extracts using HPLCDAD. Journal of Chromatographic Science, 53(4), 478-483.

Winckler, J., 1974. Vital staining of lysosomes and other cell organelles of the rat with neutral Red. Prog. Histochem. Cytochem., 6 (3), 1-91.

Zhou, C., Luo, Y., Lei, Z. and Wei, G., 2018. UHPLC-ESI-MS Analysis of Purified Flavonoids Fraction from Stem of Dendrobium denneaum Paxt. and Its Preliminary Study in Inducing Apoptosis of HepG2 Cells, Evidence-Based Complementary and Alternative Medicine. https://doi.org/10.1155/2018/8936307. 